\title{
El Maestro Ahumada
}

Ramón Corbalán

Rev Chil Cardiol 2010; 29: 381

Señor Editor:

A la edad de 95 años falleció recientemente el Dr. Jorge Ahumada Lemus, quien se desempeñó como cardiólogo y docente en la cátedra de Medicina Interna que encabezaba el Profesor Óscar Avendaño en el Hospital Clínico de la Universidad de Chile. Durante su trayectoria profesional se distinguió como un excelente clínico y docente, tanto en Pre como en Post Grado. Su actitud y conducta con los pacientes sirvieron de modelo para muchos alumnos de medicina, los que independientemente de su vocación definitiva, encontraron en el Dr. Ahumada un modelo a seguir. De ahí que se le considerara como el Maestro Ahumada por varias generaciones.

Junto a otros colegas visionarios el Dr Ahumada fue uno de los fundadores y más tarde Presidente de la Sociedad Chilena de Cardiología (1961). En la misma época y dada la coexistencia de varios servicios de Medicina en el Hospital José Joaquín Aguirre contribuyó a la formación del Centro de Cardiología de ese hospital, lugar de encuentro y de análisis de destacados cardiólogos de la época.

El Dr. Ahumada cultivó siempre el bajo perfil, siempre dispuesto a servir y sin figurar. Al jubilar, se incorporó silenciosamente a un movimiento religioso, donde colaboró en la atención médica primaria a pacientes sin recursos económicos. Hombre de bien, fundó una numerosa familia de la cual se sentía legítimamente orgulloso.

Nuestro homenaje postrero a un Maestro de la Cardiología

Dr. Ramón Corbalán H

Corbalan@med.puc.cl

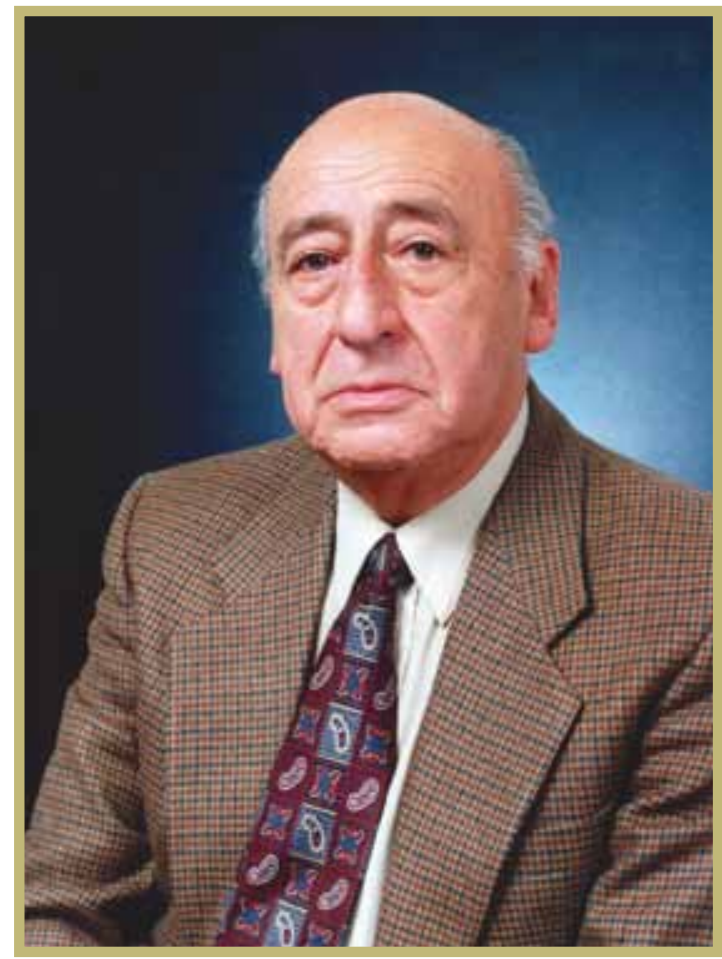

